\title{
Informatics Olympiads in Turkey: Team Selection and Training
}

\author{
Tolga CAN ${ }^{1}$, İ. Onur SIĞRCI², Osman ABUL ${ }^{3}$, M. Fatih DEMIRCí ${ }^{3}$ \\ ${ }^{1}$ Department of Computer Engineering, Middle East Technical University, Ankara, Turkey \\ ${ }^{2}$ Department of Computer Engineering, Yıldız Technical University, Istanbul, Turkey \\ ${ }^{3}$ Department of Computer Engineering, TOBB University of Economics and Technology, \\ Ankara, Turkey \\ e-mail:tcan@metu.edu.tr,ionur@yildiz.edu.tr, \{osmanabul,mfdemirci\}@etu.edu.tr
}

\begin{abstract}
In this country report, we present the yearly activities related to Turkish team selection and training for national and international olympiads in informatics. First, we outline the organizational structure and describe the scientific and administrative components. We, then, describe the several stages of team selection, which start with a nation-wide written test administered in selected cities in Turkey. Each stage is followed by two week long training camps. In these camps, students are taught the IOI curriculum and they engage in programming competition practices. In this report, we give the details of curriculum organization and test preparation. We conclude with medal statistics covering the last 22 years of the Turkish IOI team.
\end{abstract}

Keywords: IOI Country Report, Turkey.

\section{Introduction}

Turkey has been actively participating in the International Olympiads in Informatics (IOI) since the IOI'93 in Argentina. The continued support of the government funding agency TÜBITAK, the Scientific and Technological Research Council of Turkey ${ }^{1}$, the universities, and the IOI alumni help ensure that IOI remains a tradition among algorithms and programming enthusiasts in high schools. The first curriculum, training materials, and team selection tasks were developed by a team of faculty members lead by professors Göktürk Üçoluk, İsmail Hakkı Toroslu and Faruk Polat from the Department of Computer Engineering, Middle East Technical Univerity (METU). ${ }^{2}$ Today, the preparation, team selection, and organization for IOI participation of Turkey are conducted via a well-established work-flow (Fig. 1).

\footnotetext{
1 http://www.tubitak.gov.tr/en

2 http://www.ceng.metu.edu.tr
} 


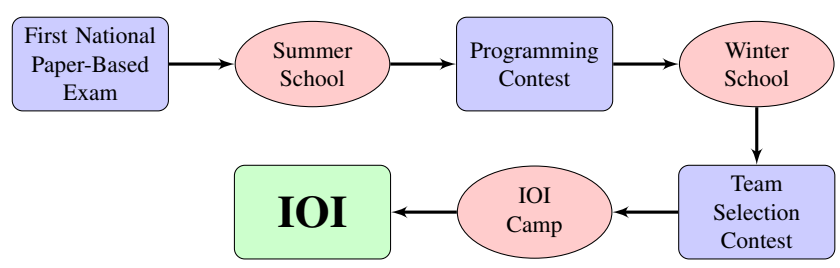

Fig. 1. Overview of the team selection and IOI organization in Turkey.

TÜBİTAK is a critical stakeholder, which provides the finances and maintains the organizational structure of the olympiads in Turkey, not only in Informatics, but also in other fields, such as Mathematics, Chemistry, Physics, and Biology. An official scientific executive committee, consisting of three academics from universities, is formed by TÜBİTAK each year. This committee is reponsible for all the scientific matters from task preparation and training to team selection. The scientific committee works in collaboration with TÜBİTAK for administration of a nation-wide first-stage selection exam, for organization of training camps, and for all administrative tasks regarding participation in that year's IOI. The scientific executive committee also recruits faculty members, interested graduate students, and alumni from previous years to teach the IOI curriculum (IOIS, 2013) effectively and help students practice for the competition during the training camps.

Being organized by an offical body, the participants of the National Olympiads in Turkey and the member of the Turkish IOI Team are also recognized officially by the Ministry of Education and the Higher Education Council of Turkey. Successful students are awarded additional points at the nation-wide university entrance exam and medal winners are granted acceptance to any Computer Science/Engineering Department of their choice at a state university in Turkey.

In the following sections of this national report, we give details of the entire workflow of Informatics Olympiads organization and preparation in Turkey. We also give the medal statistics covering the last 22 years of the Turkish IOI team. Finally, we conclude with a brief summary and an outlook for the future IOIs.

\section{Team Selection and Training Camps}

The national paper-based exam is held to select students that will participate in the summer school. Once the programming contest is done after the summer school, students with high scores are invited to the winter school, after which the final team selection is done. The IOI camp is held one week before the actual IOI to get the team prepared for IOI . TÜBİTAK organizes each stage (Fig. 1).

The team is selected after 3 contests and 2 training camps. After the final training camp, the students attend the final team selection contest. In this section, information will be given about contests and training camps. 


\subsection{The First Stage Exam}

The first stage exam is a written exam in which nearly 1300 students from all over Turkey participate. It is paper-based, takes 2.5 hours, and consists of 50 multiple choice questions (QFSE). The exam is generally held in May.

The point distribution of the questions in the exam is as follows: $15 \%$ intelligence skills, 30\% basic algorithm knowledge, 25\% maths and 30\% C programming language.

A sample programming question and its solution is given below:

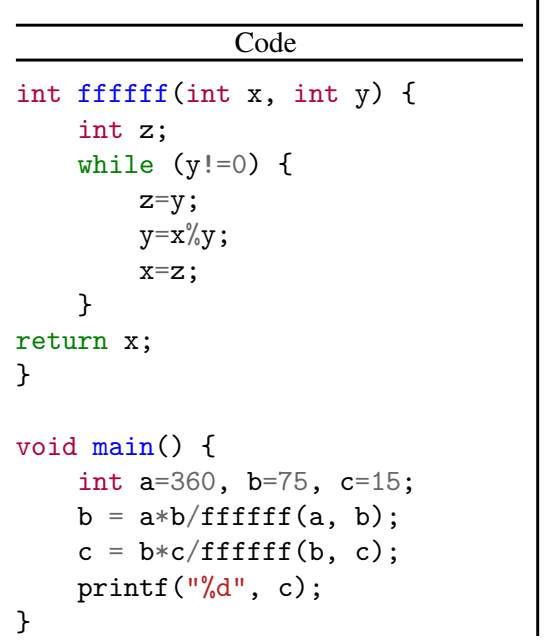

\begin{tabular}{l} 
What would be the output of the code? \\
A) 25 \\
B) 225 \\
C) 1125 \\
D) 1800 \\
E) None \\
\hline \\
Answer \\
ffffff function is to calculate the greatest \\
common divisor of $x$ and $y . L C M(a, b)=$ \\
$\quad a \times b$ \\
$G C D(a, b)$, so the $13^{\text {th }}$ line indicates that \\
$L C M(360,75)=1800$ and the $14^{\text {th }}$ line \\
indicates that $L C M(1800,15)=1800$. In \\
conclusion, the correct answer is D.
\end{tabular}

After the first stage exam, the top 55 students qualify for the second stage. In genereal, higher participation from the more populated cities such as İstanbul, Ankara, and İzmir is observed. In Fig. 2, the location of these cities on the geographical map of Turkey is shown. In addition to high level participation, these cities are also the most successful ones. Since 1993, 88 students from Turkey have participated in IOIs. 85 of these students have been from these three cities.

\subsection{The Summer Training Camp}

Approximately, 55 top students from the first stage exam attend the scientific camp that lasts for two weeks, beginning in late August and ending in early September. The students and lecturers are accomodated at a five-star hotel in Afyon (as shown in Fig. 2).

The lecturers in this scientific camp are usually academics from the most respected universities in Turkey. Additionally, graduates who have participated in the past IOIs in recent years also help the new students in the training camps.

The curriculum of the camp is in parallel with the training curriculum adopted in other countries such as Russia (Kiryukhin, 2007) and Serbia (Ilic and Ilic, 2012) and includes all the content of the second exam, which is listed below. Note that, due to the relatively heavier schedule of the first training camp, the subject of Graph Theory is divided among 


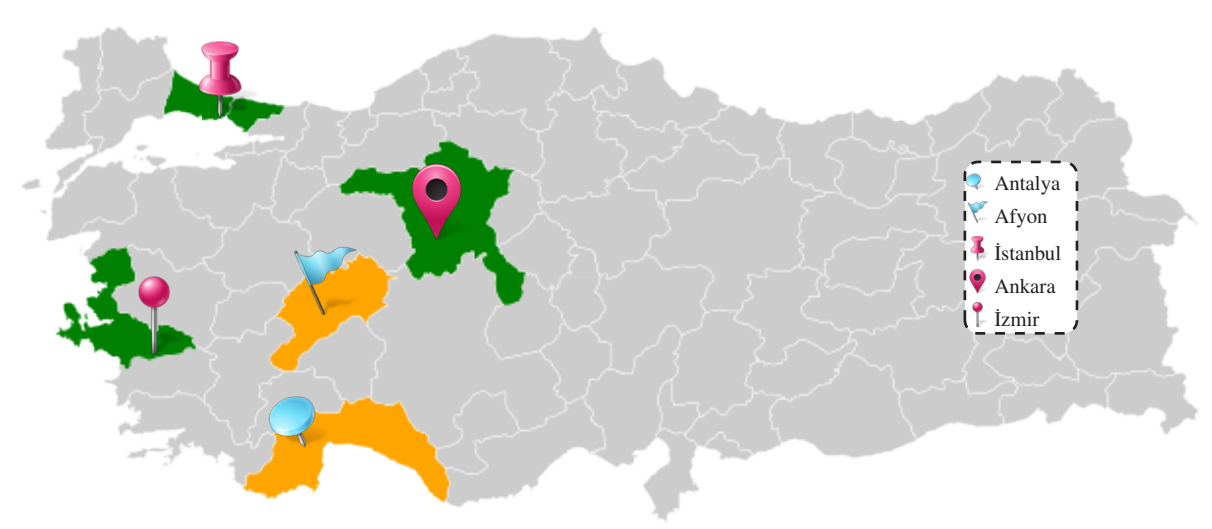

Fig. 2.Althoughthefirststage exam is nation wide, ahigherparticipation in this exam is observed from more populated cities such as Ankara, İstanbul, and Izmir. The summer and winter camps are held in Afyon and Antalya, respectively. These cities are colored in the map.

the two training camps and some basic graph algorithms such as "finding the connected components in graphs" are left for the second training camp (see Section 2.4).

- Basic Data Structures: Linked lists, stacks, queues, trees, binary trees, heaps.

- Sorting and Searching: Bubble sort, insertion sort, selection sort, quick sort, merge sort, heap sort, counting sort, radix sort, sequential search, binary search, basic space search, hashing.

- Standard Template Library (STL).

- Dynamic Programming: Longest common substring, knapsack problem, matrix chain product, longest increasing subsequence, Kadane's algorithm, greedy algorithms.

- Graphs and Basic Graph Algorithms: Graph traversal, Dijkstra's shortest path, Floyd-Warshall algorithm, Prim's and Kruskal's algorithms for minimum spanning tree, topological sort.

- Maths and Number Theory: Modular arithmetic, GCD-LCM, Euler-FermatEuclid.

Theorems, primarity test, integer factorization, Chinese remainder theorem, fast exponential, matrix exponential, Fibonacci numbers.

\subsection{The Second Stage Exam}

The second stage exam is prepared according to IOI standards and taken by the 55 students who participated in the summer training camp. The exam is performed in two days of November and its questions are developed according to the contents of the summer school.

In each of the exam days, five hours are given to solve three tasks. The top 18 successful students are awarded national medals. The distribution of the medals is 3 gold, 6 silver and 9 bronze. 
In addition to these medals, TÜBITTAK awards students with monetary values of approximately $\$ 1500, \$ 1300$ and $\$ 1100$ for each gold, silver and bronze medal respectively.

More than this one-time monetary award, each medal winner is offered monthly scholarship, enough to cover basic living costs, extending to the end of $\mathrm{PhD}$ study for the recepient.

Besides monetary/scholarhip supports, students are entitled to additional points at the national university entrance examination.

\subsection{The Winter Training Camp}

Approximately 18 students who have passed the second stage exam attend the winter training camp that lasts two weeks in February. This time, the students and lecturers stay at a five-star hotel in Antalya (as shown in Fig. 2).

In contrast to the summer training camp, the remaining subjects of the IOI curriculum are taught in the winter training camp. Due to the fewer number of students attending the camp, the lecturers have a chance to spend more time with the students. The curriculum of the camp covers:

- Advanced Data Structures: Range minimum query, segment tree, binary indexed tree, lowest common ancestor.

- Analytic and Computational Geometry: Vectors, line, segment, circle, polygons, convex hull, plane sweep, Voronoi diagrams.

- String search: Trie, suffix array, suffix tree, Aho-Corasick algorithm, KnuthMorris- Pratt algorithm.

- Graph Algorithms: Bellman-Ford shortest path, longest path, connected components, articulation points, bridge edges, Eulerian path, Hamilton cycle.

- Game Theory: Nim game, Grundy numbers, game on graphs.

\subsection{The Team Selection Exam}

Students who have attended the winter camp take another two day long exam, which includes the content of all of the IOI curriculum, in April. Similar to the second stage exam, five hours are given to solve three tasks in each of the exam days. The best four successful students form the final team that represents Turkey in both IOI and BOI (Balkan Olympiad in Informatics).

\subsection{IOI Camp}

The national IOI team prepares for the IOI for two weeks just before the actual IOI. This preperation is usually held in Ankara, the capital of Turkey (see Fig. 2). Since 
2011, the Computer Engineering Department of TOBB University of Economics and Technology ${ }^{3}$, located in Ankara, has hosted IOI camps as well as second stage and team selection examinations. Students take exams in each day of the camp and the solutions of the questions are discussed in detail with the students in a post-exam problem solving session.

A student who wins a medal in the IOI is given an opportunity to enter a computer engineering department of any state university, regardles of his/her achievement in the national university entrance examination. In additon, some private universities offer considerable scholarships for medal-winner students. TÜBİTAK offers one-time monetary awards to IOI medal winners: approximately $\$ 8000$ for gold, $\$ 6000$ for silver and $\$ 4000$ for bronze.

Starting in 2011, we have developed www.ubilo.org (TOITS), written from scratch by a few Turkish IOI alumni, to serve as the national online judge during the three camps. Like Codeforces (www.codeforces.com), it has two main interfaces: the training interface and the contest interface.With the former, the students are assigned online tasks and their submissions are graded. The latter is more like the CMS system employed in IOI exams.

The system's language, from user interfaces to task descriptions, is in Turkish since many high-schools in the country offer only Turkish curriculum.

\section{Results and Statistics for the Last Ten Years}

Table 1 shows the medal distribution of the Turkish IOI team since the first participation in 1993 in Argentina. The first gold medal was achieved by Bar1, s Kaya in 2011 in Thailand and the second gold medal was achieved two years ago in IOI Australia by Yusuf Hakan Kalaycı. The Turkish IOI team was able to get at least one medal in all of the 22 years of attendance since 1993.

\section{Conclusions and Outlook}

Turkey has been actively participating in IOI since 1993 and a total of 55 medals have been won by the Turkish IOI teams so far.With the help of the government funding agency TÜBITTAK, the universities, and the IOI alumni, being selected as a national IOI team member attracts many high school students. Earning additional points for the national university entrance examination and even obtaining a chance to the exam-free entrance to the computer engineering department at any state university along with financial aids are the top motivations for the high school students for participating in the IOI activities in Turkey. While the medal distribution in each year varies, the gold medals were achieved within the last 4 years, showing a growing interest in IOI among Turkish students.

${ }^{3}$ http: //www.etu.edu.tr 
Table 1

Medal distribution of the Turkish IOI team since 1993

\begin{tabular}{|c|c|c|c|c|c|}
\hline \multirow[t]{2}{*}{ Year } & \multirow[t]{2}{*}{ IOI Host } & \multicolumn{4}{|c|}{ Medals } \\
\hline & & Gold & Silver & Bronze & Total \\
\hline 1993 & $\because$ Argentina & & & 3 & 3 \\
\hline 1994 & Sweden & & & 2 & 2 \\
\hline 1995 & Netherlands & & & 1 & 1 \\
\hline 1996 & Hungary & & & 2 & 2 \\
\hline 1997 & South Africa & & 1 & 2 & 3 \\
\hline 1998 & Portugal & & 2 & 1 & 3 \\
\hline 1999 & C* Turkey & & 1 & 1 & 2 \\
\hline 2000 & China & & 1 & 1 & 2 \\
\hline 2001 & Finland & & & 3 & 3 \\
\hline 2002 & South Korea & & 2 & 2 & 4 \\
\hline 2003 & UUSA & & 1 & 1 & 2 \\
\hline 2004 & 目Greece & & 1 & 1 & 2 \\
\hline 2005 & Poland & & & 1 & 1 \\
\hline 2006 & Mexico & & & 1 & 1 \\
\hline 2007 & Croatia & & 1 & 1 & 2 \\
\hline 2008 & Egypt & & & 2 & 2 \\
\hline 2009 & Bulgaria & & 1 & 3 & 4 \\
\hline 2010 & Canada & & 1 & 3 & 4 \\
\hline 2011 & Thailand & 1 & 1 & 2 & 4 \\
\hline 2012 & Italy & & 1 & & 1 \\
\hline 2013 & Australia & 1 & 1 & 1 & 3 \\
\hline 2014 & * Taiwan & & 2 & 2 & 4 \\
\hline Total & & 2 & 17 & 36 & 55 \\
\hline
\end{tabular}

\section{References}

IOI. International Olympiad in Informatics. http: / / www . ioinformatics . org IOIS (2013). The International Olympiad in Informatics Syllabus. http://people.ksp.sk/ misof/ioi-syllabus/ioi-syllabus.pdf QFSE. Questions of First Stage Exam (in Turkish).

http://www.tubitak.gov.tr/tr/olimpiyatlar/ulusal-bilim-olimpiyatlari/ icerik-bilgisayar

Kiryukhin, V. M. (2007). The modern contents of the Russian national olympiads in informatics. Olympiads in Informatics, 1, 90-104.

Ilic, A., Ilic, A (2012). IOI training and Serbian competitions in informatics. Olympiads in Informatics, 6, $158-169$.

TOITS. Turkish Olympiads in Informatics Training System. http: / / kamp. ubilo. org 


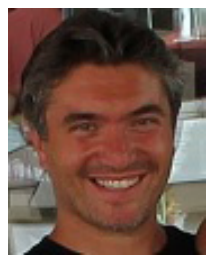

T. Can received his BSc degree in computer engineering from Middle East Technical University, Turkey, in 1998, and his PhD degree in computer science from the University of California at Santa Barbara in 2004. He is currently an associate professor in the Computer Engineering Department, Middle East Technical University, Turkey. His main research interests are bioinformatics, graph theory, and algorithms. He has worked on protein structure visualization and alignment and on construction and analysis of large-scale protein protein interaction networks. He has been teaching computational geometry in the training camps for Informatics Olympiads since 2007 and he has served on the scientific executive committee of the Informatics Olympiads in Turkey since 2011.

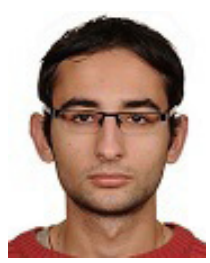

I.O. Sığırcı is a PhD student at the Computer Engineering at the Yıldız Technical University in Turkey. He is a teaching and research assistant at the Department of Computer Engineering. His main research interests are computer vision, machine learning and algorithms. He was the technical committee member at the Balkan Olympiad in Informatics 2014 in Turkey.

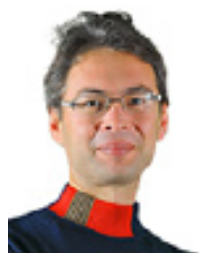

O. Abul received his $\mathrm{PhD}$ in computer science from Middle East Technical University, Turkey, in 2005. He is currently an associate professor of computer science at TOBB University of Economics and Technology, Turkey. His research interests include artificial intelligence, databases, data mining and privacy. He has been the chair of the scientific executive committee of the Informatics Olympiads in Turkey and has lead the Turkish IOI team since 2011.

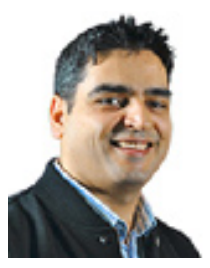

M.F. Demirci received his $\mathrm{PhD}$ in computer science from Drexel University in 2005. After working as a postdoctoral research scientist at Utrecht University, The Netherlands, he joined TOBB University of Economics and Technology, Turkey as a faculy member at computer engineering department. His research interests include structural pattern recognition in computer vision, shape indexing, and applied graph theory. He was the recipient of the best $\mathrm{PhD}$ dissertation award in engineering and physical sciences, Drexel University in 2006 and TUBITAK Career project award in 2010. He has been a member on the scientific executive committee of the Informatics Olympiads in Turkey since 2011. 